\title{
JOURNAL
}

OF THE

WORLD ASSOCIATION FOR EMERGENCY AND DISASTER MEDICINE

\section{PATRON MEMBERS}

Ambu International, Copenhagen, Denmark

Laerdal Medical, Stavanger, Norway

Pharmacia, Uppsala, Sweden

Vitalograph Limited

An Anonymous Physician

$\star \star \star \star \star$ 